\title{
El Yo y la intimidad en Ortega y Gasset
}

\author{
Self and Intimacy in Ortega y Gasset
}

\author{
Miguel RUMAYOR \\ Universidad Panamericana (México)
}

Recibido: $12 / 04 / 2014$

Aceptado: 10/09/2014

"Nada más próximo, en orden de realidad, a nosotros que nosotros mismos y sin embargo nada más lejano en el orden del conocimiento". José Ortega y Gasset

\section{Resumen}

El concepto del Yo en el pensamiento de José Ortega y Gasset aparece en repetidas ocasiones a lo largo de su obra, abordado desde diferentes perspectivas y entreverado con reflexiones intelectuales de todo tipo: psicológicas, sociológicas, artísticas, históricas, etc. Sin embargo, el enfoque de este escrito se acota a la importante relación epistemológica entre su raciovitalismo y su visión sobre la intimidad personal, centro y origen del desarrollo del Yo humano. Gracias a la riqueza de esta puede el Yo desarrollar su vocación personal hacia la autenticidad a la que está llamado, salvando de esta manera la incertidumbre, el drama y el destino al que se enfrenta a la hora de vivir la propia circunstancia.

Palabras clave: Intimidad, Ortega y Gasset, raciovitalismo, el Yo.

\begin{abstract}
The concept of the Self in the thought of Jose Ortega y Gasset appears repeatedly along his work, and was treated and mingled with different perspectives and reflections: psychological, sociological, artistic, historical, etc. Nonetheless, the focus of this writing is situated in the important epistemological relationship between his Ratio-vitalism philosophy and Personal Intimacy, which is the center
\end{abstract}


and the origin for the development of the human Self. Thanks to the enrichment of Intimacy, the Self can develop its own personal vocation to the authenticity it is called to, thus saving the incertitude, drama and destiny it faces when trying to overcome its own vital circumstance.

Keywords: Intimacy, Ortega y Gasset, Ratio-vitalism, the Self.

\section{El Yo en la obra de Ortega y Gasset}

Tal vez porque la vida intelectual de José Ortega y Gasset alcanza desde muy joven un alto nivel especulativo, es un pensador tan variado en los temas que aborda como brillante en la extensión y la forma de exponer sus ideas. Para algunos el filósofo madrileño es un autor lúcido y agudo, permanente y sutil analista de la realidad de su tiempo, de su mundo y circunstancia, diríamos usando sus propias ideas. También otros creen, puede que por lo que él mismo afirma que, "distraídos por mis imágenes, han resbalado sobre mis pensamientos"1, que se trata de un literato cuyos conceptos quedan como desleídos, brillante pero asistemáticamente, entre miles de hojas. En cualquier caso la mayoría coincide en que el método orteguiano responde a su propia naturaleza en un ir y venir entre conceptos, paradojas, fina ironía y cierto desdén hacia la metodología clásica de la tradición filosófica.

El concepto de Yo en Ortega es una reflexión también entretejida de la propia peripecia vital del autor. En este filósofo se mezclan dos realidades: la de su rico pensamiento filosófico, orientado a entender de qué estamos hablando cuando analizamos esta idea, y de otra, las múltiples experiencias de su vida, a las que se puede aplicar el que vivir "es el descubrimiento incesante que hacemos de nosotros mismos y del mundo en derredor"2. Esto nos lleva a comprender que sus cavilaciones filosóficas sobre el Yo no sigan un desarrollo lineal y evolutivo en el tiempo. No hay una conclusión filosófica clara y definitiva sobre el tema y sus ideas se encuentran dispersas en escritos de toda índole, ensayos filosóficos, artículos periodísticos, discursos políticos, etc.. Es decir, están entreveradas con reflexiones de carácter psicológico, sociológico, educativo, político, antropológico, etc., dicho con otras palabras, explicadas acorde con la razón vital orteguiana, o lo que es igual, metafísica de la vida. En este sentido tan bien es lógico que algunas de las ideas orteguianas más interesantes sobre este tema hayan quedado expuestas con ocasión de reflexiones sobre importantes personajes de la historia, entre otras como las realizadas sobre Mirabeu en 1927, de Goethe 1932, o de Velázquez en 1950 y en 1959.

\footnotetext{
1 Ortega y Gasset, J., «Pidiendo un Goethe desde dentro», Revisa de Occidente, Abril, 1932, p. 404.

2 Ortega y Gasset, J., ¿Qué es la filosofia?, en Obras Completas, vol. VIII, 1926/1932. Taurus, Madrid, 2008, p. 354.
} 
Además, desde el punto de vista del análisis filosófico a esta pluralidad de elementos que sitúan el Yo en la obra de Ortega y Gasset se añade que tratará de integrar desde un prisma antropológico y metafísico su idea de ser humano asociada al Yo. De ahí que en su planteamiento el Yo no sólo tiene detrás al hombre sino que también refleja una realidad más profunda que es el ser, es por eso en Ortega el primer ingrediente de una vida ${ }^{3}$.

Así, a lo largo de este documento se pretende explicar cómo en cada Yo, en la circunstancia y perspectiva de su propia vida, confluirán las nociones de esencia y existencia, según la peculiar metafísica orteguiana que supone una aguda crítica al idealismo, ya que para él no se puede concebir un mundo sin un Yo, ni tampoco reducir el uno al otro 4 . De ahí se deduce la idea que todo hombre deba descubrir, resolver y recrear en su intimidad su peculiar y auténtica vocación en la realidad. También, de aquí se comprende la necesidad que todas las personas poseen: "tenemos, queramos o no, que realizar nuestro "personaje», nuestra vocación, nuestro programa vital, nuestra «entelequia»" 5 . De ello se deriba que la vida que se refleja en cada Yo es para nuestro autor una realidad finita que quiere seguir siendo por siempre, permanecer de manera ejecutiva en el mundo, de ahí que para Ortega el ser humano pueda ser entendido como "un menesteroso -el menesteroso de eternidad" 6 .

Esta gran innovación orteguiana, de manera general, se puede contrastar con diferentes tradiciones y autores con gran influencia en la obra del pensandor español. Por ejemplo, al igual que Kant con su intento de ruptura con la metafísica tradicional, trata Ortega de volver a un principio de fundamentación de las cosas que no sea la verdad objetiva e invariable del realismo clásico. Kant entiende que para el ser humano es imposible llegar al noúmeno, por lo que todo análisis de las cosas va a ser forzosamente fenoménico, dando con esto pie al inicio del idealismo moderno. Sin embargo, frente al regiomontano, Ortega considera que el análisis fenoménico llevado a su extremo desemboca en la reflexividad como estructuración única de articulación de la realidad y a la autoconciencia del Yo convertida, según pretende Kant, en el sustrato último del universo ${ }^{7}$.

Por otra parte Ortega, siguiendo la crítica de Heidegger se sitúa más allá de la epokhé de la fenomenología de Husserl, considerándola una reflexión novedosa aunque insuficiente 8 , y avanza hacia una mayor concreción de las cosas junto con

\footnotetext{
3 Lasaga, J., «Las vidas contadas de José Ortega y Gasset», Anales del Seminario de Historia de la Filosofia, 2003, pp. 301-319.

4 Rodríguez Huescar, A., La innovación metafísica de Ortega. Biblioteca Nueva, Madrid, 2002, pp. 76-96 .

5 Ortega y Gasset, J., «Pidiendo un Goethe desde dentro», Revista de Occidente, Abril, 1932, p. 415.

6 Ortega y Gasset, J., Velázquez, en Obras Completas, vol. VI, 1941/1955. Taurus, Madrid, 2006, p. 622.

7 San Martín, J., La fenomenología de Ortega y Gasset. Biblioteca Nueva, Madrid, 2012, p. 135.

8 Rodríguez Huescar, A., La innovación metafisica de Ortega. Biblioteca Nueva, Madrid, 2002, pp. $102-115$
} 
el Yo y la vida. Sin duda aquí se encuentra situado su principio de la razón vital: la realidad de cada cosa asociada a la vida de cada persona. Ambos elementos son necesarios e insustituibles.

Así el Yo en Ortega no se aísla de la realidad en un mundo aparte conceptualizando esta junto a la propia conciencia de sí, sino que las cosas reobran sobre él de una manera activa y dinámica. Por eso la vida, la de que cada ser humano, va a ser el único principio de articulación metafísica. A partir de ella se fundamenta y tiene sentido cualquier realidad. De esta suerte en Ortega la realidad será en gran medida la que conforma la estructura fundamental ${ }^{9}$ del Yo, y, al mismo tiempo, ésta necesita de aquél para adquirir su plenitud ontológica, produciéndose de esta manera un reobrar mutuo, el cual llevará al Yo a ser más que una autoconciencia o autorreflexión sino a ser vida radical ${ }^{10}$.

Como aprecia Granell, frente al "ahogado Yo de la estufa cartesiana"11 que actúa como una autoconciencia que le se sitúa frente al mundo, para nuestro autor el Yo se encuentra constitutiva y originariamente en él, con salida y horizonte abierto ${ }^{12}$. De ahí que el Yo orteguiano no reconoce la verdad dentro de sí como una evidencia, como ocurre en Descartes, y de manera consecuente, ante la duda metódica propuesta por aquel pensador, origen de todo el escepticismo moderno, el pensador madrileño propugna lo que podríamos llamar como "duda realista" del Yo, la cual será el principio de su vitalismo y vocación.

De todo lo anterior se comprende la idea orteguiana de "imperativo vital" 13 inscrito en la intimidad, y esto se traduce en que el Yo se plasma en la realidad por la propia necesidad vocacional de la vida humana ante el mundo. Un imperativo que no le obliga a tener que decidirse por una vida concreta, ya que se mantiene íntimamente libre y desasido ante la realidad. Además, tiene su consecuencia más clara, como aparece tantas veces en la obra de Ortega, en el deseo que tiene la persona de llevar una vida auténtica. Esto es, estar prevenido, ya que siempre aparece la posibilidad de ser engañado ante los demás, y, lo que es peor, frente a sí mismo, ya que "el «yo» que me parece tener tan inmediato a mí, es sólo la imagen de mi «yo»"14. Como ahora se explicará, se comprende la idea que el pensador madrileño establezca una diferenciación entre diversos sustratos y profundidad del Yo en su intimidad, de forma que en cada uno de ellos se establecen y organizan distintos elementos importantes de la propia personalidad en y junto a la realidad en la que éste

\footnotetext{
${ }^{9}$ Garrigorri, P., Introducción a Ortega. Alianza, Madrid, 2008, p. 406.

10 San Martín, J., Op. Cit, pp. 157-167.

11 Granell, M., «Ortega y su filosofía», Revista de Occidente, Madrid, 1960, p. 49.

12 Vela, J., «Ortega y los existencialismos», Revista de Occidente, 1961, p. 94.

13 Ortega y Gasset, J., «Pidiendo un Goethe desde dentro», Revista de Occidente, Abril, 1932, p. 406.

14 Ortega y Gasset, J., Ensayo de estética a manera de prólogo, en Obras Completas, vol. I, 1902/1915. Taurus, Madrid, 2008, p. 669.
} 
se desarrolla, ya que "a la vera de ese mundo sólo nuestro, de ese yo individual y caprichoso, hay otro yo que piensa la verdad común a todos, la bondad general, la universal belleza"15.

\section{El Yo orteguiano: metafísica y ética entre la razón y la vida}

Ya desde 1923 en su famoso ensayo El tema de nuestro tiempo y en 1931 en su escrito ¿Qué es el conocimiento?,16 Ortega considera que la razón sirve a la vida, y entiende ésta, al igual que Dilthey, como resistencia, lo cual le lleva a no afirmar con rotundidad una idea radical de las cosas y la realidad. Quizá por eso nuestro autor tampoco hablará nunca con gran determinación, como lo hará posteriormente su discípulo Xavier Zubiri17, del Fundamento último, invariable y absoluto de lo real, Dios, el cual es para este último un asunto clave para comprender el ser personal en el que en última instancia debe arraigarse el Yo. Es lógico que por tanto la construcción del Yo y la metafísica orteguiana sea perspectivista y, para algunos autores, se asome a las puertas del relativismo.

Para Ortega la vida de cada persona es un problema por resolver, la cual consite en un permanente tratar con la incertidumbre y alteración del mundo en torno a sí. De ahí que la dinamicidad, el cambio constante y la trasformación de la realidad, son parte de la historia de cada hombre, por eso "nuestra vida es ante todo toparse con el futuro"18 y unido a esto también observa "para el hombre, vivir es, desde luego, y antes que otra cosa, esforzarse en que haya lo que aún no hay; a saber, él mismo, aprovechando para ello lo que hay; en suma, es producción"19. Así, somos extraños ante lo natural 20 , por eso las cosas materiales que aparecen en el mundo son sólo para Ortega, en relación al hombre, pragmatas, puras practicidades ${ }^{21}$ de las que el Yo inapelablemente tiene que dar cuenta en relación a sí y al sentido de cada cosa. Sólo aquello que nos afecta importa positiva y negativamente, de ahí el valor

15 Ortega y Gasset, J., La Pedagogía Social como programa político, en Obras Completas, vol. II, 1916. Taurus, Madrid, 2005, p. 94.

16 Ortega y Gasset, J., ¿Qué es el conocimiento?, en Obras Completas, vol. IV, 1926/1931. Taurus, Madrid, 2008, pp. 571-593.

17 Cfr. Rumayor, M., El Yo en Xavier Zubiri. Servicio de Publicaciones de la Universidad de Navarra, Pamplona, 2013.

18 Ortega y Gasset, J., ¿Qué es la filosofía?, en Obras Completas, vol. VIII, 1926/1932. Taurus, Madrid, 2008, p. 358.

19 Ortega y Gasset, J., Ensimismamiento y alteración, en Obras Completas, vol. V, 1932/1940. Taurus, Madrid, 2006, pp. 573-574.

20 Ortega y Gasset, J., El mito del hombre allende la técnica, en Obras Completas, vol. VI, 1941/1955. Taurus, Madrid, 2006, p. 812.

21 Vela, F., op. cit, 71. 
de la experiencia, no entendida desde el punto de vista empírico sino como vida personal. Allí donde comparece el presente y el futuro de cada hombre.

Con las cosas del mundo subsiste en el Yo el deseo íntimo y constante de conocimiento, de identidad y estabilidad en el tiempo ante el que sólo puede dar cuenta la razón humana. De ahí que el sentido de la identidad y pertenencia, tan desarrollados en Ortega entre otros a través de su reflexión sobre el tema de España, sean elementos fundamentales para el logro de la estabilidad vital en el ser humano. Podemos decir que tal serenidad vital influye en el equilibrio psicológico de todo hombre y se alcanza siempre, si así fuera, de modo parcial, sin desprenderse de la incertidumbre ante la vida, y es provocada por medio de la estabilidad metafísica en la que se asienta en último término todo Yo. Esta también tiene que ver con el entendimiento del pasado, con el presente, y con el cambio que forzosamente produce el tiempo en la vida de la persona. Por eso la circunstancia en este autor es tan importante, porque el Yo se sitúa íntimamente ante ella haciendo referencia a estos tres elementos que le orientan y le sitúan en una metafísica basada en la singularidad 22 íntima, en la que se desarrolla la propia vida del Yo23.

De forma que la vida del hombre para Ortega es metafísica ${ }^{24}$. De aquí nace el problema tensional y de todo el racioavitalismo orteguiano, de la relación de la razón y la vida, del ser con la razón, y, de manera particular, esta problemática se puede acotar en la relación a la realidad del mundo y al Yo, ya que "vivir es, de cierto modo, tratar con el mundo, dirigirse a él, actuar en él, ocuparse de él. De aquí que sea al hombre materialmente imposible, por una fuerza psicológica, renunciar a poseer una noción completa del mundo, una visión integral del Universo"25. En este sentido, como resalta Atencia ${ }^{26}$, parece existir una relación entre los planteamientos de Ortega y Bergson, ya que ambos filósofos critican con energía el concepto de inteligencia occidental firmemente anclado, o bien en un idealismo intelectual ajeno

\footnotetext{
22 Iuculano, J., Abaunza, G., «The Relevance of the Metaphysics of Ortega y Gasset for Psychology», Journal of Theoretical and Philosophical Psy, vol. 26, 2006, pp.189-204.

23 «Yo espero que a estas alturas ninguno de ustedes confunda ya esa realidad que cada cual llama "su vida" con su yo. Yo no soy más que un ingrediente de mi vida: el otro es la circunstancia o mundo. Mi vida, pues, contiene ambos dentro de sí, pero ella es una realidad distinta de mí. Yo vivo, y al vivir estoy en la circunstancia, la cual no soy yo. La realidad de mi yo es, pues, secundaria a la realidad integral que es mi vida; encuentro aquélla -la de mi yo- en ésta -en la realidad vital. Yo y las circunstancias formamos parte de mi vida. Ahora sí que podemos sin error asegurar que yo formo parte de algo, a saber, de mi vida». Ortega y Gasset, J., Principios de Metafísica según la razón vital curso 19321933, en Obras Completas, vol. VIII, 1926/1932. Taurus, Madrid, 2008, p. 598.

24 Ibid, 633.

25 Ortega y Gasset, J., ¿Qué es la filosofia?, en Obras Completas, vol. VIII, 1926/1932. Taurus, Madrid, 2008, p. 263.

26 Atencia, J. M., «Razón, intuición y experiencia de la vida. Coincidencias y divergencias entre H. Bergson y J. Ortega y Gasset», Anales del seminario de Metafísica, 36, 2003, pp. 71-76.
} 
al Yo, o en un realismo rígido distinto y absoluntamente indiferente al mismo: "esto que Bergson llama «buen sentido» es lo que yo he llamado muy formalmente «razón vital», una razón más amplia que la otra, para la cual son racionales no pocos objetos que frente a la vieja raison o razón conceptual o razón pura son, en efecto, irracionales"27.

Por eso para Ortega toda pregunta sobre el ser de las cosas, es al mismo tiempo y casi siempre de manera implícita, en la confrontación de la razón con la realidad, un ejercicio íntimo del Yo que consiste en ponerle en contacto con lo real y que conlleva una pregunta personal sobre la propia vida del Yo y su sentido. De lo que se deduce que en este autor no podemos hablar nunca de la contemplación filosófica y su crecimiento como de un ir lentamente desligándonos de las ataduras de la realidad, sino más bien de lo contrario, se trataría de un proceso que consiste en ir paulatinamente adentrándonos a la dinamicidad de la vida, según la perspectiva de cada pesona, de manera que: "La perspectiva [la de cada Yo, podríamos añadir a esta cita] es uno de los componentes de la realidad. Lejos de ser su deformación, es su organización. Una realidad que vista desde cualquier punto resultase siempre idéntica es un concepto absurdo". 28

Por tanto y para clarificar las anteriores ideas, podemos decir que en Ortega existen, siguiendo el mismo análisis que realiza García Morente ${ }^{29}$, dos tipos de acciones que puede realizar el Yo. Por un lado las que no son exclusivas del hombre: moverse, comer, dormir, etc., y por otro las específicamente humanas, las cuales estarán encaminadas a transformar el propio ser actual en lo que el Yo íntimamente quiere realmente llegar a ser. Serán aquellas otras acciones de la razón aplicadas a la vida, que se orientan a conducir su realidad, la realidad del Yo presente, hacia esa realidad futura cuya imagen actúa sobre el presente: todas esas acciones orientadas a trasformar el hombre en el ser que aún no es pero que quiere vocacionalmente, ya que, como observa nuestro autor: "conviene no defraudar la sublime necesidad que de nosotros tiene, e hincándonos bien en el lugar que nos hallamos, con una profunda fidelidad a nuestro organismo, a lo que vitalmente somos, abrir bien los ojos sobre el contorno y aceptar la faena que nos propone el destino: el tema de nuestro tiempo"30.

Por eso un peligro constante aparece en la vida del Yo cuando este no se encuentra orientado a la excelencia del pensamiento, a dar lo mejor de sí, lo que su inti-

\footnotetext{
27 Ortega y Gasset, J., ¿Qué es la filosofía?, en Obras Completas, vol. VIII, 1926/1932. Taurus, Madrid, 2008, p. 276.

28 Ortega y Gasset, J., El tema de nuestro tiempo, en Obras Completas, vol. III, 1917/1925. Taurus, Madrid, 2005, p. 613.

29 García Morente, M., La esencia de la Universidad. Rialp, Madrid, 2013, p. 49.

30 Ortega y Gasset, J., El tema de nuestro tiempo, en Obras Completas, vol. III, 1917/1925. Taurus, Madrid, 2005, p. 616.
} 
midad le solicita y pasa a ser masa social amorfa. Entonces surge para Ortega el peligro: “de que esa invasión de lo externo nos desaloje de nosotros mismos, vacíe nuestra intimidad, y exentos de ella quedemos trasformados en postigos de camino real por donde va y viene el tropel de las cosas"31.

Insertar el sentido de la realidad en el Yo, en su vida y devenir, en su circunstancia y perspectiva, supone, como se decía más atrás, el permanente riesgo de caer en el relativismo o en la subjetividad absoluta del propio Yo. Por eso, tal vez de la manera en la que el pensamiento de Ortega puede ser entendido fuera de la circularidad a la que avoca lo dicho, en el que Yo, realidad y verdad se acaban enredando en una madeja indiscernible, sea relacionar la inteligencia personal con la ética y el uso de la propia libertad. De manera más concreta, no sólo con el ejercicio de esta última sino con la capacidad que tiene ésta de determinarse por el bien, la verdad y la belleza. En cierto modo se trataría, sin abandonar las lindes del planteamiento orteguiano, de derivar del raciovitalismo una sólida ética de la vida, de la buena vida, podríamos decir como Aristóteles. La razón así se presentará como un instrumento para el logro de la libertad y, más concretamente, para que el Yo alcance la felicidad. Así, la vida humana no es un drama vocacional sin sentido, un devenir hacia un lugar anhelado y desconocido a un tiempo, como podría deducirse de una cierta lectura del pensamiento orteguiano, para pasar a convertirse en una búsqueda universal, filosófica y personalísima del bien, de la verdad y la belleza.

Se entiende de todo lo dicho que para nuestro autor no pueda consistir la felicidad personal en un abandono del Yo en los apetitos, las llamadas pasiones en el pensamiento clásico. De aquí tal vez también proviene el famoso orteguiano "sentido deportivo de la existencia”, de voluntad de superación y lucha constante. Mantener la energías de la propia vida, siempre en vilo, evitando el desánimo y conbatiendo el propio desaliento, realidad que, como explica Gracia ${ }^{32}$, fue tan presente en la obra y vida de Ortega.

El Yo es consciente de la pérdida de vida, de razón vital, cuando no existe el orden sobre el mundo pasional. Aunque también es cierto que para Ortega, fuertemente influido por Nietzsche, el Yo se extravía cuando la reflexión sobre lo que está sucediendo es intensa y constante, racionalista diría el filósofo alemán, y le deja por ello imposibilitado para vivir con intensidad. Esta es para Ortega otra forma de perder la intensidad de la vida, el único elemento para nuestro autor con que se puede desarrollar la felicidad del hombre. Por eso para Ortega, al igual que el autor de Zaratustra, en cierto modo vivir y sentirse vivir es incompatible ya que cuanto menor sea la expansión de nuestras actividades, en mayor grado seremos espectadores de nosotros mismos: "y el espectáculo que se nos ofrece es nuestro yo atado

31 Ortega y Gasset, J., Meditaciones del Quijote, en Obras Completas, vol. I, 1902/1915. Taurus, Madrid, 2008, p. 780.

32 Gracia, J., José Ortega y Gasset. Taurus, Madrid, 2014. 
como un Prometeo que pugna por moverse y no lo logra; nuestro yo convertido en puro anhelo, en propósitos irrealizados, en tendencias paralíticas y conatos reprimidos"33.

Esta última idea se entiende para Ortega, tal y como desarrollará Xavier Zubiri con posterioridad en El Hombre y Dios (1984), en que las normas de comportamiento, la ética, la moral, no pueden ser ajenas a la propia vida íntima y vital del Yo y aparecer como reglas externas, ya que: "Una moral geométricamente perfecta, pero que nos deja fríos, que no nos incita a la acción, es subjetivamente inmoral. El ideal ético no puede contentarse con ser él correctísimo: es preciso que acierte a excitar nuestra impetuosidad" 34 .

\section{La intimidad del Yo}

Para Ortega la vida se sabe a sí misma, más no es autoconciencia plena. Esta es una gran aportación de nuestro autor al pensamiento, la cual consiste en establecer la diferencia en el Yo entre el ser ejecutivo y el ser objetivo ${ }^{35}$. Así la intimidad aparece junto al Yo y el mundo, y por eso aunque el ensimismamiento ${ }^{36}$ es un elemento fundamental en Ortega, sin embargo se puede afirmar que el Yo se forma de una manera más profunda que por la propia torsión consciente que puede realizar el hombre en soledad, sumergido en la búsqueda hacia los abismos de la autenticidad de la propia interioridad. Somos, para Ortega, en gran medida extraños frente al misterio arcano e insondable de nuestro $\mathrm{Yo}^{37}$.

Esta idea se puede comprender en gran medida si se entiende que el ensimismamiento orteguiano no es el creador del Yo, la causa y origen del mismo. Ni tampoco, claramente, de la intimidad personal. El ensimismamiento es verdaderamente el único modo para Ortega en que se puede desarrollar la vida interior del Yo,

\footnotetext{
33 Ortega y Gasset, J., Teoría de la felicidad, en Obras Completas, vol. II, 1916. Taurus, Madrid, 2005, p. 223.

34 Ortega y Gasset, J., El tema de nuestro tiempo, en Obras Completas, vol. III, 1917/1925. Taurus, Madrid, 2005, p. 586.

35 San Martín, J., La fenomenología de Ortega y Gasset. Biblioteca Nueva, Madrid, 2012, p. 163.

36 Rodríguez González, M., La cuestión del Yo en Ortega, en El primado de la vida (cultura, estética y política en Ortega y Gasset), AA.VV. Ediciones de la Universidad de Castilla la Mancha, Cuenca, 1997, pp. 15-23.

37 «lo que en cada instante vemos de nuestro ser interior es sólo un pequeño trozo: estas ideas que ahora pensamos, este dolor que sufrimos, esta imagen que se pinta dentro de nuestro escenario íntimo, esta emoción que ahora sentimos - pero este pobre montoncillo de cosas que ahora vemos nosotros es sólo lo que en cada caso se adelanta a nuestra mirada vuelta hacia adentro, es sólo como el hombro de nuestro yo completo y efectivo -el cual queda al fondo como una gran cuenca o serranía de que en cada instante vemos sólo el rincón de un paisaje» Ortega y Gasset, J., ¿Qué es la filosofía?, en Obras Completas, vol. VIII, 1926/1932. Taurus, Madrid, 2008, pp. 280-281.
} 
pero también es una manifestación secundaria del mismo. Es decir, en Ortega la existencia primera del Yo, junto con la circunstancia, provocarán, frente a la alteración exterior, el desarrollo de la intimidad y la vocación del Yo hacia la vida.

Entender esta última idea de esa manera, es el único modo posible de romper con la circularidad ${ }^{38}$ de un Yo que, como Sísifo, se vuelve una y otra vez sobre sí mismo para descubrirse, inventarse y justificar la propia vida y la vocación a la que está llamado. Además, este planteamiento justifica plenamente la existencia en sus obras de la llamada "voz insobornable" de la conciencia, como aquel principio inscrito originalmente en el Yo, previo a cualquier modo de profundización sobre el mismo.

De ahí también que en Ortega sea muy relevante el reconocimiento a la peculiaridad y diferencia que posee cada intimidad personal ${ }^{39}$. La intimidad de cada Yo es esencialmente, no sólo accidentalmente, diferente. Es anterior a la propia conciencia del mundo. Sólo reparo en quien soy verdaderamente cuando me desentiendo de lo que me rodea y me retiro del mundo ${ }^{40}$, por eso ésta produce el mundo interior, el estado de ánimo, el tono y el sentimiento íntimo, que se estructuran en una cierta forma espacio-temporal mediante la cual el Yo, que en Ortega es psicofísi$c o^{41}$, se orienta y asume en solitario su propia problematicidad vital frente a las cosas reales.

Aquí forzosamente aparece el cuerpo humano como elemento clave del Yo, sin el cual, a diferencia de lo que sucede en Descartes, éste no puede ser entendido en una totalidad aislada o res extensa, ya que "nuestro cuerpo desnuda nuestra alma, la anuncia y la va gritando por el mundo" 42 . El cuerpo, por tanto, se relaciona con lo que nuestro autor denomina Yo vital, relacionado con las energías psico-corporales, que junto al Yo del alma, que tiene que ver con los sentimientos, deseos y emociones y el Yo espiritual, que se relaciona con la inteligencia y la voluntad, conforman el entramado en el que se constituye, estructura y expresa la intimidad personal43.

Por ello para Ortega el proceso de crecimiento de la propia intimidad conlleva una forma de espiritualización de la vida y cierta separación interior de la corpora-

38 Lasaga, J., Notas sobre la Antropología defectible de Ortega, en Las dimensiones de la vida humana. Ortega, Zubiri, Marías y Laín Entralgo, AA. VV. Biblioteca Nueva, Madrid, 2010, p. 66.

39 Sellés, J. F., Luces y sombras en tres versiones distintas de la Intimidad humana: Ortega, Zubiri y Marias, en Las dimensiones de la vida humana. Ortega, Zubiri, Marías y Laín Entralgo, AA.VV. Biblioteca Nueva, Madrid, 2010, pp. 272-275.

40 Ortega y Gasset, J., Principios de Metafisica según la razón vital curso 1932-1933, en Obras Completas, vol. VIII, 1926/1932. Taurus, Madrid, 2008, p. 587.

41 Tabernero Del Río, S., Libertad, razón y educación en J. Ortega y Gasset, Foro de Educación, no 11, 2009, p. 92.

42 Ortega y Gasset, J., Sobre la expresión, fenómeno cósmico, en Obras Completas, vol. II, 1916. Taurus, Madrid, 2005, p. 683.

43 Cfr. Ortega y Gasset, J., Vitalidad, alma, espiritu, en Obras Completas, vol. II, 1916. Taurus, Madrid, 2005. 
lidad y del llamado mundo ejecutivo, ya que "no hay más remedio que quedarse sólo de cuando en cuando para hacer bien las cuentas de nuestros asuntos" 44 . Por eso concluye en relación a esta idea defendiendo una cierta aristocracia espiritual entre la calidad de la libertad entre las diferentes expresiones del Yo y el nivel ético y vital de cada persona, ya que, "es forzoso decir que cuanto más violento sea un acto psíquico, más bajo en la jerarquía del alma, más próximo al ciego mecanismo corporal, más distante del espíritu. Y, viceversa, conforme nuestros sentimientos van tiñéndose de más de espiritualidad, van perdiendo violencia y fuerza mecánica. Siempre será más violenta la sensación de hambre en el hambriento que el apetito de justicia en el justo"45.

De esa expansión interior que venimos hablando también se deduce el hecho de que para nuestro autor la metafísica sea soledad ${ }^{46}$, íntimo y personal convencimiento del Yo ante las cosas. El descubrimiento de esta subjetividad como retirada del mundo queda en Ortega filiado en la religión cristiana, ya que "el cristianismo es el descubridor de la soledad como sustancia de la cosas" 47 . Aunque, no cabe duda, que en tal acción de recogimiento también existe un paralelismo con la epojé de la fenomenología 48 .

En la intimidad, para Ortega, el Yo puede constatar las exigencia de lo real a la que está llamada la propia vida y responder así con valentía, al igual que en Nietzsche, siendo o no auténtico, vitalmente creativo. De ahí que la soledad también produzca en todo ser humano permanente inseguridad. Buscamos a qué atenernos, dominar la realidad, el ser del mundo y nuestro Yo. Por eso podemos percibir que entre los diferentes tipos de personas "hay una proporción diferente entre el número de cosas que hace porque las ha visto hacer o las ha oído decir y las que provienen de su propia iniciativa, las que son invención suya. Y tendremos dos casos extremos: el que en su hacer, en su conducta corporal o espiritual, no inventa apenas nada, sino que se adapta a las pautas dominantes en la sociedad o grupo social donde vive, y aquél en quien, por el contrario, predomina la invención propia. El primero es un hombre o una mujer convencionales, sin personalidad, sin intimidad. Es una marioneta movida por los hilos mecánicos de la sociedad. El segundo, es el hombre o las mujeres originales, geniales, el hombre o la mujer que viven de lo que en su intimidad nace y brota. Esto es la espontaneidad" 49 .

\footnotetext{
44 Aguado, E., Ortega y Gasset. Epesa, Madrid, 1970.

45 Ortega y Gasset, J., Estudios sobre el amor. Círculo de Lectores, Barcelona, 1969, p. 94.

46 Ortega y Gasset, J., Principios de Metafisica según la razón vital curso 1932-1933, en Obras Completas, vol. VIII, 1926/1932. Taurus, Madrid, 2008, p. 634.

47 Ortega y Gasset, J., ¿Qué es la filosofía?, en Obras Completas, vol. VIII, 1926/1932. Taurus, Madrid, 2008, p. 327.

48 San Martín, J., La fenomenología de Ortega y Gasset. Biblioteca Nueva, Madrid, 2012, p.131.

49 Ortega y Gasset, J., Ensayo sobre la Criolla, en Obras Completas, vol. IX, 1933/1948. Taurus, Madrid, 2009, p. 246.
} 
El ensimismamiento orteguiano al que tiene que llegar la intimidad del Yo, no se produce como un proceso de atontamiento personal o de distracción frente a las cosas, sino como resultado de un distanciamiento momentáneo de las realidades mundanales. Una característica frente a los animales profundamente humana ${ }^{50}, \sin$ la cual la persona se convierte en una realidad vitalmente alterada, vertida hacia fuera y por tanto excéntrica. Porque sucede que en la alteración el hombre pierde lo más esencial y propiamente humano. La posibilidad de meditar, de recogerse dentro de sí mismo para saber en lo que cree y lo que no, lo que de verdad estima y detesta. La alteración le obnubila, le obliga a actuar mecánicamente en un ciego sonambulismo ${ }^{51}$.

En conclusión puede decirse que para nuestro autor ser verdadera e íntimamente libres es la actitud más sabia a la que puede llegar el Yo, la cual, en ningún momento, anulará la permanente inseguridad ante la vida. No en vano la función del filósofo, frente a todo academicismo, es en Ortega una actitud meditativa que nace de la profundidad de la intimidad, la cual trata una y otra vez, de manea vocacional, y en soledad, de encontrar en la realidad aquello que le falta, lo que se decubre, también, como una carencia del propio Yo en la realidad, ya que: "las cosas cuando faltan empiezan a tener un ser. Por lo visto el ser es lo que falta en nuestra vida -el enorme hueco o vacío de nuestra vida-, que el pensamiento en su esfuerzo incesante se afana en llenar" 52 . Por eso, como se decía más atrás, el Yo de educada sensibilidad se sitúa ante las circunstancias de una manera prudente y en cierto modo insegura 53 .

\section{Vocación y destino, autenticidad y drama}

Para José Ortega y Gasset la vida es proyectiva y al mismo tiempo destino vital y acontecimiento dramático, en donde las circunstancias exteriores sitúan permanentemente la libertad humana y donde el Yo tratará de plasmarse con éxito en cada momento del devenir vital. Por eso: "el afán de realizar nuestra vocación, de conseguir ser el que somos es lo que nutre nuestras energías y las mantiene tersas" 54 .

\footnotetext{
50 Ortega y Gasset, J., El mito del hombre allende la técnica, en Obras Completas, vol. VI, 1941/1955. Taurus, Madrid, 2006, p. 815.

51 Ortega y Gasset, J., Ensimismamiento y alteración, en Obras Completas, vol. V, 1932/1940. Taurus, Madrid, 2006, p. 534.

52 Ortega y Gasset, J., Principios de Metafisica según la razón vital curso 1932-1933, en Obras Completas, tomo VIII, 1926/1932. Taurus, Madrid, 2008, p. 606.

53 Ortega y Gasset, J., La razón histórica, en Obras Completas, vol. IX, 1933/1948. Taurus, Madrid, 2009 , p. 627.

54 Ortega y Gasset, J., Velázquez, en Obras Completas, vol. VI, 1941/1955. Taurus, Madrid, 2006, p. 640 .
} 
En este sentido también añade nuestro autor "somos nuestro Destino, somos proyecto irremediable de una cierta existencia. En cada instante de la vida notamos si su realidad coincide o no con nuestro proyecto, y todo lo que hacemos lo hacemos para darle cumplimiento" 55 . Por eso Ortega desde muy joven se adentra en las Meditaciones del Quijote (1914) en esta situación paradigmática en la intimidad del hombre, donde vocación y destino se entreveran de modo indiscernible creando en el Yo una permanente y lúdica voluntad de aventura ${ }^{56}$.

El Quijote representa metafóricamente los afanes de la vida humana, de un Yo rico en intimidad y con una clara vocación y proyecto de vida, que debe conformar su realidad personal circunscrita, también, entre sus locas fantasías. Es por lo que para Ortega la postura vital de Alonso Quijano se puede ver metafóricamente como universalmente simpática ${ }^{57}$, debido a que su pathos es en cierta medida el común a toda la humanidad. Se enfrenta el Caballero a las vicisitudes de llevar a cabo su vida frente a un entorno hostil, donde la realidad metafísica y su intimidad son en ocasiones difícilmente discernibles. Al igual que afirma Scheler58, se ofrecen constantemente como resistencia y posibilidad de afirmación del Yo, esto es, en todo su conjunto como "«cosas que ya sabíamos», es decir, de cosas que ya estaban ante nosotros, que existían para nosotros, y nuestra definición no va a hacer sino descubrirnos íntimos y habituales amigos que teníamos desde siempre sin saberlo de verdad hasta ahora" 59 .

La subjetividad y la objetividad de la ética se concretan en Ortega en la vocación 60 ante lo real que posee todo hombre. Tal y como se está explicando, para el Yo es tan importante el mundo interior como el exterior, ya que en ambos se encuentra la posibilidad de realización del propio proyecto de vida, o lo que Ortega llamará circunstancia vital. Ésta puede ser comprendida como aquello que exteriormente pasa en la realidad y lo que interiormente le sucede al Yo; como Quijote, idealidad y realidad, cultura y vida, buscando así de esta manera Ortega la síntesis entre el mundo mediterráneo y el alemán61. Ambos aspectos, interior y exterior, son límite y posibilidad vocacional del Yo, ya que: "es, pues, para el hombre, imposible estar sin una orientación ante el problema que es su vida. Precisamente porque la vida es siempre en su raíz desorientación, perplejidad, no saber qué hacer, es tam-

\footnotetext{
55 Ortega y Gasset, J., No ser hombre de partido, en Obras Completas, vol. IV, 1926/1931. Taurus, Madrid, 2005, p. 308.

56 Cerezo Galán, P., La voluntad de aventura. Ariel, Madrid, 1984.

57 Carpintero, H., «Ortega y El "Quijote". Los primeros apuntes». Anales del Seminario de Historia de la Filosofía, vol. 23, 2006, pp. 240-243.

58 Scheler, M., Idealismo y realismo. Buenos Aires, Nova, 1962, pp. 99-100.

59 Ortega y Gasset, J., Principios de Metafisica según la razón vital curso 1932-1933, en Obras Completas, vol. VIII, 1926/1932. Taurus, Madrid, 2008, pp. 578-579.

${ }^{60}$ Cerezo Galán, P., José Ortega y Gasset y la razón práctica. Biblioteca Nueva, Madrid, 2011, p. 215. 61 Ibid, p. 90.
} 
bién siempre esfuerzo por orientarse, por saber lo que son las cosas y él entre ellas. Porque tiene que habérselas con ellas, necesita saber a qué atenerse con respecto a ellas"62.

De aquí nace la idea clave en relación a la famosa frase del filósofo: "Yo soy yo y mi circunstancia, y si no la salvo a ella no me salvo yo"63. El íntimo deseo de salvar la circunstancia no se entiende como un anhelo religioso o trascendental, entendidos este como acciones extramundanas, sino más bien consiste en la asunción radical de dos aspectos: la propia circunstancia y la vida del Yo "ambos polos integrados en el circuito de la vida en reflexión"64. Esto pasa en nuestro autor por caminar entre dos planteamientos. Por un lado se encuentra el relativismo el cual Ortega rechaza, ya que esto supondría convertir al Yo en pura circunstancia y por tanto hacer desaparecer la vida personal, y por otra parte para el pensador madrileño el Yo no puede ser sólo cogito cartesiano, pura ipseidad y reflexión solisipista, lo que equivaldría a sumirlo en el pozo del subjetivismo y del idealismo y alejarlo de la vida, ya que "la razón no puede, no tiene que aspirar a sustituir la vida" 65.

De tal suerte que la vocación en la propia vida debe de ser construida en el tiempo, en cada situación ya que: "sin hombre no hay misión, podemos ahora añadir: sin misión no hay hombre" 66 . El Yo salva la circunstancia vital en absoluta soledad. Nadie puede suplantarle en esta tarea, origen de un cierto desasosiego, a la que cada uno se enfrenta personalmente. He aquí la importancia que otorga Ortega al peso de la intimidad de cada persona, como se decía más atrás, la cual es única, insustituible origen y fundamento de la vocación ante nuestra libertad en lo real.

En nuestro autor un incuestionable anhelo de autenticidad traspasa de parte a parte al Yo, el cual le empuja a recrear personalmente sus ideales en la propia circunstancia. Por eso, en Ortega para que algo sea un ideal no basta que parezca digno de serlo por razones éticas, de gusto o de conveniencia, sino que ha de tener la cualidad de encantar y atraer todas las energías personales, de encajar perfectamente en nuestra sensibilidad y vocación. De otro modo será sólo un espectro de ideal, un ideal paralítico incapaz de tender la ballesta de nuestro espíritu. Por eso, para el pensador español, de las dos caras que el ideal tiene sólo se ha atendido hasta ahora la que da a lo más excelso y se ha olvidado la otra, la que se vierte hacia el interior de la economía vital67. Hay pues entonces una vocación inevitable hacia la realidad

62 Ortega y Gasset, J., Principios de Metafisica según la razón vital curso 1932-1933, en Obras Completas, vol. VIII, 1926/1932. Taurus, Madrid, 2008, p. 632.

63 Ortega y Gasset, J., Meditaciones del Quijote, en Obras Completas, vol. I, 1902/1915. Taurus, Madrid, 2008, p. 757.

${ }^{64}$ Cerezo Galán, P., José Ortega y Gasset y la razón práctica. Biblioteca Nueva, Madrid, 2011, p. 95.

65 Ortega y Gasset, J., Meditaciones del Quijote, en Obras Completas, vol. I, 1902/1915. Taurus, Madrid, 2008, p. 784.

66 Ortega y Gasset, J., Misión del bibliotecario, Obras Completas, vol. V, 1932/1940. Taurus, Madrid, 2006, p. 351.

67 Ortega y Gasset, J., Estudios sobre el amor. Círculo de Lectores, Barcelona, 1969, p. 13. 
que también se concreta y solicita una permanente formación y enriquecimiento de la propia intimidad y los ideales y creencias en ella inscritos, ya que el Yo "es intimidad, es lo que está dentro de sí, es para sí, sin embargo, es preciso que sin perder esa intimidad el yo encuentre un mundo radicalmente distinto de él, y que salga fuera de sí a ese mundo"68.

La búsqueda y el logro de la propia autenticidad vocacional consiste en una tarea de recogimiento interior, tal y como se decía, de ensimismamiento lo llamará Ortega, gracias al cual la persona es capaz de penetrar en los propios ideales y plasmar su vida en un proyecto vital auténtico: "En rigor bastaría, pues, con que descendiésemos al propio corazón y, eliminando cuanto sea afán individual, privada predilección, prejuicio o deseo, prolongásemos las líneas de nuestro apetitos y tendencias esenciales hasta verlas converger en un tipo de vida. Pero yo comprendo que esta operación, en apariencia tan sencilla, no lo es para quien no está habituado a los rigores y precisiones del análisis psicológico. Nada menos habitual, en efecto, que esa torsión de la mente hacia dentro de sí misma. El hombre se ha formado en la lucha con lo exterior, y sólo le es fácil discernir las cosas que están fuera. Al mirar dentro de sí se le nubla la vista y padece vértigo"69.

\section{El Yo y los otros}

El Yo se roza con la realidad, como decíamos, una y otra vez. Más concreta y claramente, con la vida de los otros, que son otros Yo con los que conformará su propia vida personal. Es aquí, como se explica en el Hombre y la Gente donde se produce ese paso fundamental del sujeto a la sociedad a través de la intermediación de la vida de cada Yo. Por eso para el filósofo, familiarizado con el ámbito de la sociología, los usos sociales ${ }^{70}$ son los que en gran medida moldean y educan al Yo, ya que estos aparecen como posibilidades de encuentro con los otros, con su mundo y circunstancia las cuales, a través del paso de las generaciones, quedan plasmadas en la vida social. Aquí juega una baza importante el concepto Orteguiano de "usos" y de "vigencia social". Éste es uno de los elementos sociales fundamentales que conforma la circunstancia en la que cada Yo se ve arrojado al teatro de su propia existencia junto con los otros.

La vigencia de la realidad, aquello que en cada momento se vive en cada sociedad y conforma, por así decirlo, el "uso" de cada cosa, se plasma en costumbres y

68 Ortega y Gasset, J., ¿Qué es la filosofía?, en Obras Completas, vol. VIII, 1926/1932. Taurus, Madrid, 2008, p. 333.

69 Ortega y Gasset, J., El tema de nuestro tiempo, en Obras Completas, vol. III, 1917/1925. Taurus, Madrid, 2005, p. 570.

70 Ferreiro Lavedán, M. I., La teoría social de Ortega y Gasset: los usos. Biblioteca Nueva, Madrid, 2005 pp. 122-132. 
modos de entender y vivir la realidad. No cabe duda que para Ortega tales usos y vigencias, sin determinadar las ideas personales de cada individuo, como ocurre en Durkheim con el llamado "inconsciente colectivo", van situando social e íntimamente al Yo frente a los demás. Mucho más se podría decir de las creencias, frente a las ideas en la vida social, como señala nuestro autor en distintos momentos, no sólo le hacen ser sino estar en ellas de un modo mucho más personal.

Podríamos decir que tales elementos actúan sobre el Yo individual de dos modos simultáneos. Por un lado le presionan y le solicitan un modo de ser en la sociedad, pero por otro confrontan con lo que es y le exigen una respuesta de autenticidad personal frente a los otros Yoes. Por eso para nuestro autor el verdadero "poder de lo social" consiste en la influencia y reflejo que ejercen unas personas sobre otras 71 .

En este sentido se puede decir que la visión moderna del Yo a la que se enfrenta la filosofía orteguiana es sin duda la relación originaria que el Yo establece con los otros, por eso la máxima kantiana "obra de tal manera que no emplees sólo como medios a los otros hombres" es analizada en repetidas ocasiones a lo largo de su obra filosófica. Aunque no es menos cierto que el Yo, a diferencia del sujeto trascendental kantiano, no es algo acabado y perfecto sino más bien un elemento dinámico y necesariamente moldeado en la relación con los otros y sus circunstancias, en el mutuo conocimiento de sus virtudes y defectos, ya que "mi conocimiento de los tús va podando, cercenando a ese yo vago y abstracto pero que, en abstracto, creía ser todo (...) De este modo, es el mundo de los tús y merced a éstos donde se me va moldeando la cosa que yo soy, mi yo"72.

Para nuestro autor, en la conformación de los usos sociales, de las creencias e ideas, jugarán en la sociedad un papel importante los hombres egregios, de excelsa intimidad. Ortega, como refleja en sus múltiples ensayos y reflexiones psicológicas sobre grandes personalidades de la historia (Velázquez, Goethe, Napoleón, Maura, etc.,) entiende que la asunción y la vivencia de la propia circunstancia vital no siempre se ha producido en todos los hombres de la misma manera, hecho que, por ser así ha condicionado fuertemente el devenir de pueblos y sociedades. Por tanto, es claro que aunque como observa Ferreiro ${ }^{73}$, para Ortega la opinión de los ciudadanos es siempre poder social, también es adecuado decir que el efecto del mismo no se concentra en todas las personas de igual modo. Queda explicada con elocuencia la diferencia entre personas en la siguiente reflexión: "un hombre eminente, en vista

\footnotetext{
71 Ortega y Gasset, J., El poder de lo social, en Obras Completas, vol. IV, 1926/1931. Taurus, Madrid, 2005, pp. 99-107.

72 Ortega y Gasset, J., El hombre y la gente, en Obras Completas, vol. X, 1949/1955. Taurus, Madrid, 2010, pp. 253-254.

73 Ferreiro Lavedán, M. I., La teoría social de Ortega y Gasset: los usos. Biblioteca Nueva, Madrid, 2005, pp. 117-122.
} 
de su ejemplaridad, fue dotado por la muchedumbre dócil de autoridad pública. Muere aquel hombre y su autoridad queda como un hueco social, especie de forma anónima que otros individuos vendrán a ocupar unas veces con mérito bastante, otras sin él. A la postre, el prestigio de la autoridad durará lo que dure el recuerdo de las personas que la ejercieron"74.

Así deja claro Ortega en la La Rebelión de las Masas (1929) la tarea de liderazgo y formación social que tienen estos individuos, los cuales no son siempre ricos ni poderosos, ni pertenecen necesariamente a una clase social determinada. $\mathrm{Su}$ situación de autoridad con respecto al Yo de los otros, tal vez por el hecho de haber asumido íntimamente su vocación y proyecto personal de una manera mucho más autética y comprometida que el resto, consiste en dotarles de una seguridad de la que ellos originariamente carecen en su encuentro con las cosas. Esto sólo se produce por medio de un convencimiento personal y libre de aquellos que son mandados, por eso observa: "la sociedad se divide en gente que manda y gente que obedece; pero esta obediencia no podrá ser normal y permanente sino en la medida en que el obediente ha otorgado con íntimo homenaje al que manda, el derecho a mandar"75.

Por otra parte el concepto social y político del Yo en Ortega no es netamente individualista ni participa, por así decir, sólo de las llamadas teorías de los grandes hombres, ya que también tiene influencias del personalismo comunitario de Mounier y la filosofía neotomista de Maritain, de la visión de la comunidad que se asocia y desprende de ésta, como se puede ver cuando observa: "Jesús parece amonestarnos suavemente: no te contentes con que sea ancho, alto y profundo tu yo: busca la cuarta dimensión de tu yo, la cual es el prójimo, el tú, la comunidad"76.

Ante estos dos elementos, el valor de lo individual y la importancia de lo social, podemos decir que en el planteamiento orteguiano si la igualación entre el Yo y el Tú de los otros sería un punto de vista que eleva la dignidad personal, sin embargo también considera que podría ser germen de grandes frustraciones vitales. El asunto es que si de manera velada tal planteamiento social suprime la libertad como autonomía, la cual en la filosofía de Ortega debe subsistir a toda costa, puede llevar a que el Yo quede ahogado en su vitalidad y perdido íntimamente en su circunstancia. Es una posibilidad que existe en el Yo frente a cualquier tú. De ahí que para Ortega la decisión personal, el acto autónomo de libertad del Yo, es tan importante como el hecho mismo de tratar al otro como un tú: "Hay aquí un margen para el arbitrio, margen que no sería posible si los demás individuos humanos fueran realmente «Yo». El «tú»», el «él», son, pues, ficticiamente «yo»»77.

\footnotetext{
74 Ortega y Gasset, J., España invertebrada. Alianza, Madrid, 1981, p. 89.

75 Ibid, p. 89.

76 Ortega y Gasset, J., La Pedagogía social como programa político, en Obras Completas, vol. II, 1916. Taurus, Madrid, 2005, p. 102.

77 Ortega y Gasset, J., Ensayo de estética a manera de prólogo, en Obras Completas, vol. I, 1902/1915. Taurus, Madrid, 2008, p. 667.
} 
Parece por ello que no existe una visión plenamente personalista-comunitaria en el planteamiento orteguiano, ya que para nuestro autor el Yo nunca puede ser un tú, ni tampoco aspirar a serlo. Esto es una ficción romántica que viene fungiendo como el último coletazo para salir del racionalismo cartesiano, o dicho de otra manera, el postrero intento de salvar al Yo del aislamiento donde la posición individualista sobre el cogito le habría acabado arrastrado. De manera que ahogándole en el falso emotivismo de un Yo que se hace en los demás más que sí mismo superaría todas sus frustraciones solitarias. Sin embargo para Ortega toda entrega personal del Yo es también una constante y esforzada afirmación íntima y personal frente a una realidad dinámica y cambiante que son los otros. Esa aspiración en nuestro autor, como se explica en el libro Estudios sobre el amor (1939), queda bien tematizada con la idea del amor entre hombre y mujer, donde se explica con profundidad que el Yo para amar tiene que ser siempre sí mismo de forma auténtica frente al otro.

Estas ideas son clave para comprender cómo el pensamiento orteguiano, desde un punto de vista ético, no puede ser entendido como individualismo ya que, en relación a los otros, para Ortega la dignidad de la decisión libre es tan grande como la elección por el bien mismo. Una sociedad formada por Yoes tratados como si fueran fines absolutos no es una sociedad de personas sino de individuos. Pequeños dioses solitarios que, obviamente en el fondo de sus intimidades han sido instruidos para no decidir por otra cosa que no sean ellos mismos, y cuando optan por el prójimo, exigidos por el individualísimo imperativo categórico, no luchan íntima y auténticamente por entregar lo que son, ya que no están capacitados para hacerlo. Se hayan amarrados por el dogmatismo y el rigorismo moral, por la ética y la concepción kantiana del Yo, que periclita en una sutil y, en este caso, perniciosamente auténtica, búsqueda de uno mismo a través de la vida social.

La orteguiana inestabilidad del Yo, la inseguridad, la desazón vital, son propias de un ser que comparece siendo a la vez sí-mismo y circunstancia, realidad y relación con los otros. Es allí, como se decía más atrás, donde se fraguan las ideas que se "tienen" y las "creencias" en las que el ser humano está78. Hay que añadir que estos elementos aparecieron de una manera muy significativa en la propia vida de Ortega y Gasset y en las vocaciones que tensan el arco de su espíritu hacia polos contrapuestos: vida pública y política, metafísica y reflexión, acción y contemplación, estar en la política actuando y en ella reflexionando.

Dado lo dicho también podemos comprender el valor de la educación, y cómo para nuestro autor la formación del Yo en la vida social se da gracias a ella y a la cultura, las cuales contribuyen al enriquecimiento de la intimidad y a la construcción permanente de lo que denomina como "temple emotivo", crisol por el que irán pasando de manera armónica las vicisitudes de la propia vida y la de los otros, "que

78 Ortega y Gasset, J., Carácter histórico del conocimiento, en Obras Completas, vol. VI, 1941/1955. Taurus, 2006, p. 15. 
será para su vida, dice con ribereña comparación, lo que es la quilla que para la nave que comienza por poner el carpintero de ribera"79.

Para concluir este epígrafe, como se ha dicho anteriormente, el método orteguiano en relación a lo social está basado en gran parte en el vitalismo nietzscheano y en la idea de la expansión de la vida. Por eso tal vitalismo no coincide tampoco con el naturalismo de Rousseau, ya que Ortega no nos habla del valor de la expansión de la espontaneidad natural de la vida humana en su encuentro con los otros, como si se trataran de fuerzas físicas que deben de ordenarse por una suerte de contrato social. Una pedagogía vitalista para Ortega significa la búsqueda y promoción de esa fuerza interior que, frente al racionalismo, articula y da sentido a la realidad en y con los otros, en contra del naturalismo ilustrado, supera con creces cualquier reduccionismo biológico, porque "en lugar de apresurarse en convertirnos en instrumentos eficaces para tales o cuales formas transitorias de la civilización, debe fomentar con desinterés y sin prejuicios el tono vital primigenio de nuestra personalidad" 80 .

\section{Conclusión}

A lo largo de estas líneas se ha tratado de explicar cómo, aunque si bien el Yo orteguiano sólo puede ser entendido a partir del marco conceptual del pensamiento moderno, sin embargo estructuralmente difiere en mucho del cogito cartesiano o del sujeto trascendental kantiano. Es un Yo, frente al de estos dos que, desde el primer momento comparece a un mismo tiempo junto y con la realidad, como dos elementos de un todo que no puede ser completamente escindido. Por este motivo tampoco el Yo en Ortega puede ser visto desde la óptica del realismo clásico que el pensador madrileño rechaza, ya que en cierta manera esta hace desaparecer el valor que tiene el devenir de la propia vida en la conformación de la realidad en la que el Yo se encuentra inscrito. En este sentido, circunstancia vital y Yo se coimplican en una mutua necesidad en la que ambas deben de ser respetadas.

El mundo interior del ser humano, el intus con sus diferentes sustratos y niveles de intensidad: el Yo vital, Yo del alma, y el Yo espiritual, es para Ortega un elemento profundamente relacionado con su raciovitalismo y su peculiar noción de la realidad a la que el Yo vocacionalmente se encuentra llamado.

Aquí nace el peso de la intimidad del Yo, en la perplejidad e incertidumbre con la que éste, en cada momento, tiene que salvar la circunstancia y peripecia de la pro-

79 Ortega y Gasset, J., ¿Qué es la filosofía?, en Obras Completas, vol. VIII, 1926/1932. Taurus, Madrid, 2008, p. 294.

80 Ortega y Gasset, J., Ensayos filosóficos. Biología y Pedagogía, en Obras Completas, vol. II, 1916. Taurus, Madrid, 2005, p. 418. 
pia vida. La realidad cambiante existe provocando incertidumbre en relación al mundo interior del Yo, de ahí que deba plasmarse en ella de forma libre y auténtica, pues es la autenticidad, en la filosofía orteguiana, el destino último y concreto al que aspira todo ser humano en la vida, la personal vocación en lo real. Un anhelo vital que según su fuerza e importancia es apreciado en Ortega como la misión personal de todo Yo en su viaje hacia el fondo de sí. Esta vocación en Ortega también se encuentra relacionada con el disfrute de la vida, con la realidad y con uno mismo, algo que, sin duda, hizo pensar tanto a Ortega con su propio devenir vital.

Tal autenticidad y su riqueza queda puesta especialmente de manifiesto entre aquellos individuos de intimidad superior, los que son capaces de vivir en la realidad con mayor sensibilidad y sentido frente a la masa social amorfa. Son estos, por la influencia o poder que ejercen sobre los otros, los que tienen una mayor responsabilidad en el devenir de la sociedad en su conjunto, de las vigencias, ideas y creencias, que en esta aparecen en cada momento.

Por ello, lo social, frente lo que el Yo choca, se afirma y consolida, toma en relación a lo dicho una gran importancia, ya que conforma la estructura de usos y costumbres entre los que se forma histórica y generacionalmente la altura metafísica de cada época. Es allí donde el Yo debe afirmar su propia e íntima identidad, junto y con los otros.

\section{Referencias bibliográficas}

Aguado, E., Ortega y Gasset. Epesa, Madrid, 1970.

AtenCiA, J. M., «Razón, intuición y experiencia de la vida. Coincidencias y divergencias entre H. Bergson y J. Ortega y Gasset», Anales del seminario de Metafísica, 36, 2003.

Carpintero, H., «Ortega y El "Quijote". Los primeros apuntes». Anales del

Seminario de Historia de la Filosofía, vol. 23, 2006.

Cerezo Galán, P., José Ortega y Gasset y la razón práctica. Biblioteca Nueva, Madrid, 2011.

Cerezo Galán, P., La voluntad de aventura. Ariel, Madrid, 1984.

Ferreiro LaVedÁn, M. I., La teoría social de Ortega y Gasset: los usos. Biblioteca

Nueva, Madrid, 2005.

GARrigorri, P., Introducción a Ortega. Alianza, Madrid, 2008.

García Morente, M., La esencia de la Universidad. Rialp, Madrid, 2013.

Gracia, J., José Ortega y Gasset. Taurus, Madrid, 2014.

Granell, M., "Ortega y su filosofía”, Revista de Occidente, Madrid, 1960.

Iuculano, J., Abaunza, G., «The Relevance of the Metaphysics of Ortega y Gasset

for Psychology», Journal of Theoretical and Philosophical Psy, vol. 26, 2006. 
LaSAga, J., «Las vidas contadas de José Ortega y Gasset», Anales del Seminario de Historia de la Filosofia, 2003, pp. 301-319.

Lasaga, J., Notas sobre la Antropología defectible de Ortega, en Las dimensiones de la vida humana. Ortega, Zubiri, Marías y Laín Entralgo, AA. VV. Biblioteca Nueva, Madrid, 2010.

Ortega y Gasset, J., Carácter histórico del conocimiento, en Obras Completas, vol. VI, 1941/1955. Taurus, Madrid, 2006.

Ortega y Gasset, J., El mito del hombre allende la técnica, en Obras Completas, vol. VI, 1941/1955. Taurus, Madrid, 2006.

Ortega y Gasset, J., El hombre y la gente, en Obras Completas, vol. X, 1949/1955. Taurus, Madrid, 2010.

Ortega y Gasset, J., El poder de lo social, en Obras Completas, vol. IV, 1926/1931. Taurus, Madrid, 2005.

Ortega y Gasset, J., El tema de nuestro tiempo, en Obras Completas, vol. III, 1917/1925. Taurus, Madrid, 2005.

Ortega y Gasset, J., Ensayo de estética a manera de prólogo, en Obras Completas, vol. I, 1902/1915. Taurus, Madrid, 2008.

Ortega y Gasset, J., Ensayos filosóficos. Biología y Pedagogía, en Obras Completas, vol. II, 1916. Taurus, Madrid, 2005.

Ortega y Gasset, J., Ensayo sobre la Criolla, en Obras Completas, vol. IX, 1933/1948. Taurus, Madrid, 2009.

Ortega y Gasset, J., Ensimismamiento y alteración, en Obras Completas, vol. V, 1932/1940. Taurus, Madrid, 2006.

Ortega y Gasset, J., Estudios sobre el amor. Círculo de Lectores, Barcelona, 1969. Ortega y Gasset, J., España invertebrada. Alianza, Madrid, 1981.

Ortega y Gasset, J., La Pedagogía Social como programa político, en Obras Completas, vol. II, 1916. Taurus, Madrid, 2005.

Ortega y Gasset, J., La razón histórica, en Obras Completas, vol. IX, 1933/1948. Taurus, Madrid, 2009.

Ortega y Gasset, J., Meditaciones del Quijote, en Obras Completas, vol. I, 1902/1915. Taurus, Madrid, 2008.

Ortega y Gasset, J., «Pidiendo un Goethe desde dentro», Revisa de Occidente, Abril, 1932.

Ortega y Gasset, J., Principios de Metafísica según la razón vital curso 19321933, Obras Completas, vol. VIII, 1926/1932. Taurus, Madrid, 2008.

Ortega y Gasset, J., ¿Qué es filosofia?, en Obras Completas, vol. VIII, 1926/1932. Taurus, Madrid, 2008.

Ortega y Gasset, J., ¿Qué es el conocimiento?, en Obras Completas, vol. IV, 1926/1931. Taurus, Madrid, 2008.

Ortega y Gasset, J., Sobre la expresión, fenómeno cósmico, en Obras Completas, vol. II, 1916. Taurus, Madrid, 2005. 
Ortega y Gasset, J., Teoría de la felicidad, en Obras Completas, vol. II, 1916. Taurus, Madrid, 2005.

Ortega y Gasset, J., Velazquez, en Obras Completas, vol. VI, 1941/1955. Taurus, Madrid, 2006.

Ortega y Gasset, J., Vitalidad, alma, espíritu, en Obras Completas, vol. II, 1916. Taurus, Madrid, 2005.

Rodríguez GonzÁlez, M., La cuestión del Yo en Ortega, en El primado de la vida (cultura, estética y politica en Ortega y Gasset), AA.VV. Ediciones de la Universidad de Castilla la Mancha, Cuenca, 1997, pp. 15-23

Rodríguez Huescar, A., La innovación metafisica de Ortega. Biblioteca Nueva, Madrid, 2002.

Rumayor, M., El Yo en Xavier Zubiri. Servicio de Publicaciones de la Universidad de Navarra, Pamplona, 2013.

SAn MARTín, J., La fenomenología de Ortega y Gasset. Biblioteca Nueva, Madrid, 2012.

SEllÉS, J. F., Luces y sombras en tres versiones distintas de la Intimidad humana: Ortega, Zubiri y Marías, en Las dimensiones de la vida humana. Ortega, Zubiri, Marías y Laín Entralgo, AA. VV. Biblioteca Nueva, Madrid, 2010.

SCHEler, M., Idealismo y realismo. Nova, Buenos Aires, 1962.

TABERnERo Del Río, S., «Libertad, razón y educación en J. Ortega y Gasset», Foro de Educación, $\mathrm{n}^{\mathrm{o}}$ 11, 2009.

VElA, F. «Ortega y los existencialismos», Revista de Occidente, Madrid, 1961.

Miguel Rumayor

Universidad Panamericana (México)

mrumayor@up.edu.mx 